\title{
Isolation, Identification and Antimicrobial Resistance Profiles of Salmonella from Dairy Farms in Adama and Modjo Towns, Central Ethiopia
}

\author{
Abdurezak Abrar ${ }^{1}$, Takele Beyene ${ }^{1}$ and Walkite Furgasa ${ }^{2} *$ \\ ${ }^{1}$ College of Veterinary Medicine, Addis Ababa University, Addis Ababa, Ethiopia; ${ }^{2}$ School of Veterinary Medicine, \\ Wollegga University, Nekemte, Ethiopia. \\ *Correspondence: walkiteharamaya@gmail.com
}

\begin{abstract}
A cross-sectional study was carried out from February 2019 to May 2019 in Adama and Modjo aiming at isolating Salmonella from dairy cattle farms and determining the antimicrobial susceptibility testing of the isolates. A total of 117 samples from dairy farms: faces, bulk tank milk, personnel hand swab and contaminated floor samples were collected and screened for the presence of Salmonella. Ten (8.5\%) of the samples tested were found to be positive for Salmonella. Of 89 faces, 10 bulk tank milk, 9 personnel hand swab and 9 contaminated floor samples, no positive was found in the milker's hand swab samples from both Adama and Modjo areas and the isolation frequencies of Salmonella were $8.98 \%, 10 \%$, and $11.1 \%$ in faces, bulk tank milk and floor sample, respectively. The antibiogram testing revealed differential multi-drug resistance among Salmonella isolates in lactating cow and cows environment samples. Most the isolates were resistant to methicillin, streptomycin, and nalidixic acid whereas sensitivity was recorded for gentamicin. In conclusion, the relatively high resistance among the bacteria present in dairy farms could pose public health and therapeutic problems to consumers as potential vehicles of resistant Salmonella food borne infections.
\end{abstract}

Keywords: Adama, Salmonella, Antimicrobials, Dairy farms, Isolation, Modjo, and Multidrug resistance.

\section{INTRODUCTION}

Food-borne diseases are a public health problem in developed and developing countries. More than 250 different food-borne diseases have been described. Most of these diseases are infections caused by a variety of bacteria, viruses and parasites. Salmonella has been one of the most commonly reported causes of food-borne pathogens from distant and recent times (Pui et al., 2011; Hoffmann et al., 2012). According to a recent study (Kirk et al., 2015) commissioned by the WHO on the global disease burden of food-borne diseases in humans, food-borne illnesses from diarrheal and invasive non-typhoidal Salmonella enterica, resulted in the largest disease burden, highlighting the significant public health importance of Salmonella infections and the urgency for control, particularly in low-and middleincome countries where most burden of diseases and occurrence of mortality cases are reported. Salmonella species belong to Gram-negative, rod shaped, facultative intracellular bacteria that successfully infects a wide variety of hosts. Salmonella is comprised of two species, Salmonella bongori and S. enterica (Guibourdenche et al., 2010). 
Out of these 2,700 serovars, nearly 1500 belong to the $S$. enterica subsp. enterica. Serovars of the enterica sub species can be divided into three groups depending upon their ability to infect a wide variety of hosts: Serovars which have a broad host range also called as unrestricted serovars as these infect nearly all animals and pose a greater zoonotic potential than their other counterparts, Serovars which accidentally infect hosts other than their most adapted or preferred (McCuddin et al., 2006; Shahen et al., 2019), and serovars which are restricted to one specific host only. Salmonella transmits to humans can occur through several routes. these are consumption of contaminated food products (milk, eggs, and meats), direct contact with animals and their environment, cross-contamination through direct contact of foods to contaminated surfaces such as stainless steel, hanging material, knife, bucket where milk are collected are a key mechanism for pathogens to contaminate food products (Kusumaningrum et al., 2003; Uddin et al., 2017).

Excretion of Salmonella with faces can contaminate water, soil, other animals and feed. Although Salmonella primarily intestinal bacteria, due to its ubiquitous nature common in the environment and commonly found in farm effluents human sewage and in any materials subject to faecal contamination as a result it leads the contamination of milk and meat products to originate either from infected live animals or from cross-contamination while during processing. Despite the controls that have already been put into place, Salmonella infection arising from contaminated food continues to be an immense problem with millions of cases occurring annually throughout the world. In addition to the misery caused, financial loss is enormous (Hendriksen, 2003). An increasing proportion of Salmonella isolates is resistant to commonly used antibiotics in both developing and developed countries (Threlfall, 2002), and this increase is seen in both veterinary and public health sectors (Kemal, 2014; Van Boeckel et al., 2015).

Using antimicrobial agents for cattle have been implicated as a source of human infection with antimicrobial resistant (AMR) Salmonella through UniversePG I www.universepg.com direct contact with livestock and consumption of raw milk, meat and contaminated materials (Alexander et al., 2009; Sharif et al., 2019). Antimicrobial resistant Salmonella are increasing due to the use of antimicrobial agents in food animals at subtherapeutic level or prophylactic doses for growth promotion and markedly increase the human health risks associated with consumption of contaminated milk and meat products (Zewdu and Cornelius, 2009; Md et al., 2006), through mutation, acquisition of resistance encoding genes (Fluit, 2005) and irrational use of antimicrobials in food animals (Fluit, 2005; Beyene and Tesega, 2014).

In Ethiopia, as in other developing countries, it is difficult to evaluate the burden of food-borne diseases, because of the limited scope of studies and lack of coordinated epidemiological surveillance systems. In addition, under reporting of cases and the presence of other diseases considered to be of higher priority may have overshadowed the problem of food-borne diseases including Salmonellosis. Therefore, the aims of the current study were: To isolate and identify Salmonella from dairy cows' feces, personnel hand, equipment and contaminated floor sample and to evaluate the antibiogram pattern of the isolates to commonly used antibiotic agents from selected dairy farms in Modjo and Adama towns.

\section{MATERIALS AND METHODS}

Study Area - The study was conducted in Modjo and Adama towns from February 2019 to June 2019. Modjo is the administrative center of Lome district, located in the East Shewa Zone of the Oromia Region, Ethiopia. It is located at $66 \mathrm{Km}$ Southeast of Addis Ababa and lies at latitude $8^{\circ} 35^{\prime} \mathrm{N}$ and longitude $39^{\circ} 7^{\prime} \mathrm{E}$ at an altitude of 1790 meters above sea level. The area gain rainfall twice a year those known as long and short rainy season. The main rainy season extends from June to September. The average annual rainfall, temperature, and mean relative humidity are: $776 \mathrm{~mm}, 19.4^{\circ} \mathrm{C}$ and $59.9 \%$ respectively (CSA, 2005).Adama town, East Shoa, Ethiopia, which is located about $100 \mathrm{~km}$ south east of Addis Ababa at an altitude of 1650 meter above sea level. Its annual temperature ranges from 
$13.9^{\circ} \mathrm{C}-29^{\circ} \mathrm{C}$. The mean annual rainfall of the area is $1024 \mathrm{~mm}$. The livestock population of the area in 2004/2002 estimated to be 70,622 cattle, 36,142 sheep, 42,968 goats and 2,193 equines (CSA, 2005).

Study Population - The study population is lactating dairy cows in Modjo and Adama towns and the study animals were apparently healthy dairy cows in smalland large-scale dairy farms located in and around Modjo and Adama towns. The farms were selected by using simple random sampling strategies based on data obtained from both areas livestock and fishery resource development. In this study, the majority of farms found in the study areas were small scale having herd sizes not more than six cows. All of the available lactating cows present in each farm were sampled. According to personal observation, the hygienic status of the cows and their environment was more or less good even though some animals were reared under poor hygienic condition plus in a manner mixed with other activities of the households. Farm equipment used in the milking and storage of milk and personnel's (milkers') were also part of the study.

Study Design - A cross-sectional study was carried out to isolate, identify and detect antimicrobial susceptibility profile of the Salmonella from dairy farms. Sampling days were randomly assigned and each farm was visited only once during the study period. Types of sample collected include feces, bulk tank milk, milkers' hand swab, contamination of floor.

Sample Collection and Transportation - Samples from dairy cows (faces), hand swab of personnel working in the farms (milker's), from equipment and from contaminated environment (contaminated floor sample) were aseptically collected from the selected dairy farms. Samples from dairy cows were collected from apparently health lactating cows. Fresh fecal samples were collected directly from the rectum of healthy lactating dairy cows using disposable gloves into sterile plastic bags. Pooled milkers' hand swab is collected before the beginning of milking process by using a sterile cotton swab. Floor samples were collected from bedding of the animal house and from the environment and equipment which the cows feed using a sterile a sterile cotton swab and Samples were properly coded based on collection date, sample source and sample type. Source of sample was classified as animal, personnel and equipment. Types of samples collected in quantity were faces (89), pooled milkers' hand swab (9), bulk tank milk (10) and floor sample (9). Then samples were immediately transported under cold condition (ice box) to the Microbiology Laboratory of College of Veterinary Medicine and Agriculture, Addis Ababa University, Bishoft. Upon arrival, samples were processed separately by pre-enriching in preenrichment media or were stored overnight in a refrigerator at $+4^{\circ} \mathrm{C}$ until examined the next day. Then further processes were followed after samples were incubated for $24 \mathrm{hrs}$.

\section{Isolation and Identification of Salmonella}

Pre-enrichment and selective enrichment - The feces samples were pre-enriched in appropriate amount of buffered peptone water in (1:9) ratio and incubated at $37^{\circ} \mathrm{C}$ for $24 \mathrm{hrs}$. RappaportVassiliadis medium (RV) broth and Selenite (SB) broth were used for selective enrichment of the samples. About 0.5 and $\mathrm{ml}$ of the pre-enriched sample was transferred into a tube containing 10 $\mathrm{ml}$ of Rappaport-Vassiliadis medium (RV broth) and incubated at $42^{\circ} \mathrm{C}$ for 24 hours. Another $1.0 \mathrm{ml}$ of the pre-enriched broth was transferred into a tube containing $10 \mathrm{ml}$ of Selenite broth and incubated at $37^{\circ} \mathrm{C}$ for 24 hours.

Plating out and identification - Xylose lysine desoxycholate (XLD) agar plate was used for plating out and identification. A loop full of inoculums from each RV and Selenite broth cultures were plated onto XLD plate and incubated at $37^{\circ} \mathrm{C}$ for 24 hours. After incubation, the plate was examined for the presence of typical and suspect colonies. Typical colonies of Salmonella grown on XLD-agar have a black center and a lightly transparent zone of reddish color due to the color change of the media while $\mathrm{H}_{2} \mathrm{~S}$ negative variants grown on XLD agar are pink with a darker pink center. Lactosepositive Salmonella grown on XLD agar are yellow with or without blackening. Five typical or suspected colonies were selected from the 
selective plating media, streaked onto the surface of pre-dried nutrient agar plates and incubated at $37^{\circ} \mathrm{C}$ for $24 \mathrm{hrs}$. All suspected Salmonella colonies were picked from the nutrient agar and inoculated into the following biochemical tubes for identification: triple sugar iron (OXOID CM0277, England) agar, Simmon's citrate agar (HIMEDIA M099, India), Indole tests (Becton Dickinson, USA), Methyl red-Voges-Proskauer (HIMEDIA M070, India) broth and then incubated for 24 to 48 hrs at $37^{\circ} \mathrm{C}$

\section{Biochemical Confirmation of Salmonella Isolates -}

All suspected Salmonella isolates were subjected to the following biochemical tests for confirmation: Triple Sugar Iron (TSI) test, Indole test, Citrate utilization test, Methyl red test, and Vogues Proskauer (VP) test. Colonies producing red slant (alkaline), with yellow butt (acid) on TSIA with blackening due to hydrogen sulphide $\left(\mathrm{H}_{2} \mathrm{~S}\right)$ production and e (gas production) in butt, negative for Indole test, positive for Methyl red test (red broth culture), positive for citrate utilization (deep blue slant), and negative for VP test were considered to be Salmonella positive (Quinn et al., 2004). Presumptive Salmonella isolates that were found fulfilled the Salmonella characteristics on all biochemical tests indicated above were transferred and cultured on Nutrient Agar (NA) for antimicrobial sensitivity and motility tests.

Antimicrobial Susceptibility Testing - The antimicrobial susceptibility testing of the isolates was performed with Kirby-Bauer disk diffusion method according to Clinical and Laboratory Standards Institute of U.S.A (CLSI, USA) and Kirby Bauer Disk Diffusion Susceptibility Test Protocol on Muller Hinton agar medium. From each biochemically confirmed isolate, loop full of well grown colonies on nutrient agar were transferred with sterile loop into sterile tubes containing $5 \mathrm{ml}$ of normal saline solution $(0.85 \% \mathrm{NaCl})$. The inoculated colonies mixed well with saline solution by vortex until smooth suspension was formed. Saline solution (if suspension more turbid) or colonies (if suspension less turgid) were added to the suspension until it achieved to the $0.5 \mathrm{McFarland}$ turbidity standards. Then sterile cotton swab was dipped into the suspension and the bacteria were swabbed uniformly over the entire surface of Muller Hilton Agar plate. The plates were being held at room temperature for 3 minutes in bio-safety cabinet to allow drying. Ten antimicrobial disks with known concentration of antimicrobial were placed on the Muller Hinton Agar plate; nine of them in circular pattern and one at the center and the plates were incubated for $22 \mathrm{hrs}$ at $37^{\circ} \mathrm{C}$.

Each isolate was tested for a series of eleven antimicrobials: Tetracycline (TE) $(30 \mu \mathrm{g})$, Cefoxitin (FOX) $(30 \mu \mathrm{g})$, Cefuroxime $(30 \mu \mathrm{g})$, Ciprofloxacin (CIP) $(5 \mu \mathrm{g})$, Gentamycin (CN) $(10 \mu \mathrm{g})$, Nitrofurantoine (NIT) $(300 \mu \mathrm{g})$, Nalidixic acid (NA) $(30 \mu \mathrm{g})$, Streptomycin (S) $(10 \mu \mathrm{g})$, Erythromycine (ERY) (15) and Methicillin (ME) (5). The diameters of clear zone of inhibition produced by diffused antimicrobial on lawn inoculated bacterial colonies were measured to the nearest $\mathrm{mm}$ using caliper. All eleven zone of inhibition against eleven antimicrobial agents for each isolate were recorded and compared with standards and interpreted as resistant, intermediate, or susceptible according to published interpretive chart (CLSI, 2013).

Data Management and Analysis - The raw data generated from the study were arranged, organized, coded and entered to Excel spread sheet (Microsoft ${ }^{\circledR}$ office excel 2007). Then the data was analyzed using SPSS version 20 through descriptive analysis with chi-square statistics. The results of analyses were mostly described in proportion. Proportion were estimated as the numbers of samples detected positive to Salmonella from the total sample tested as well as the numbers of antimicrobial resistant isolate to the detected positive isolate.

\section{RESULTS}

Growth on Solid Media - On nutrient agar Salmonella colonies were moderately large (2-4 mm), circular with smooth surface and grayish- white in color after 24 hours at $37^{\circ} \mathrm{C}$ (Fig 1). Growth on deoxycholate agar showed slight opaque domeshaped colonies measured $(2-4 \mathrm{~mm})$ with central black spots (indicated production of hydrogen sulfide) surrounded by a zone of clearance after 48 
hours at $37^{\circ} \mathrm{C}$ (Fig 2). On triple sugar iron agar Salmonella colonies produced hydrogen sulfide which was indicated by black discoloration, gas production causes bubbles in the agar, and $\mathrm{pH}$ change was indicated by production of red color in the slant (Fig 3).

Proportion of Bacteria Isolation - Salmonella was isolated from $10 / 117(8.5 \%)$ of the total samples. Out of the 10 Salmonella isolates, $8(80 \%), 1(10 \%)$, (and $1(10 \%)$ were from feces, bulk tank milk, and floor sample, respectively (Table 1). From a total of 89 cow's feces examined, 8.98\% (8/89), 10 bulk tank milk samples, $10 \%$ (1/10), and out of 9 contaminated floor sample, $11.1 \%$ (1/9) were confirmed positive for Salmonella from both cities, Adama and Modjo.
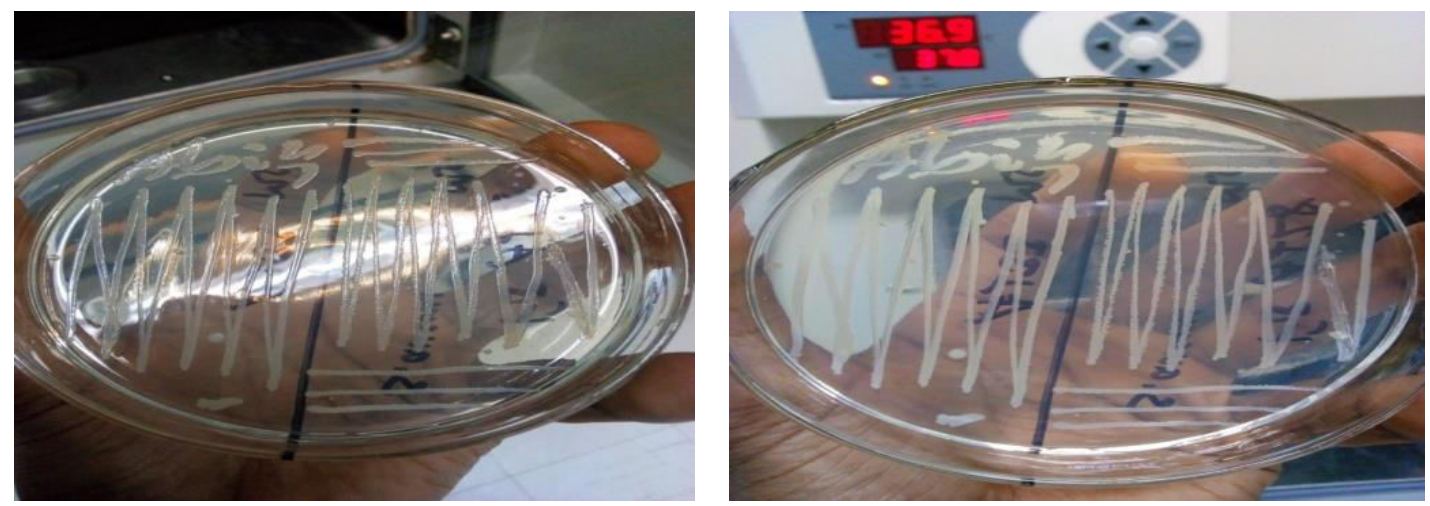

Fig 1: Growth of Salmonella on Nutrient Agar.
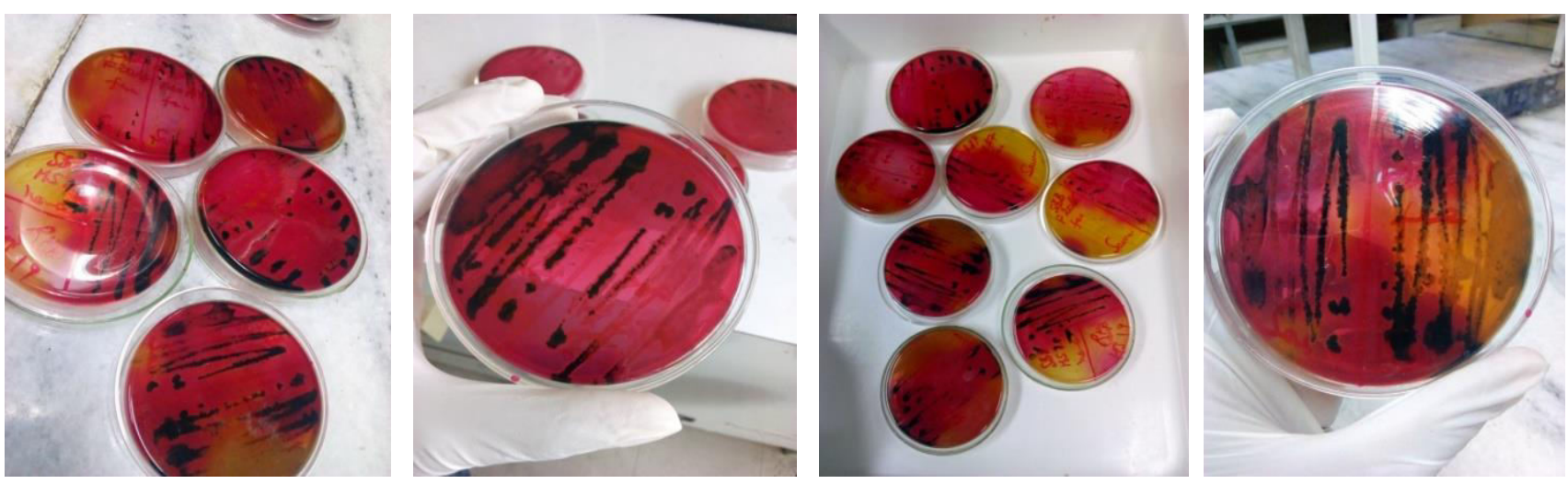

Fig 2: Growth of Salmonella on Xylose Lysine Desoxychocolate.
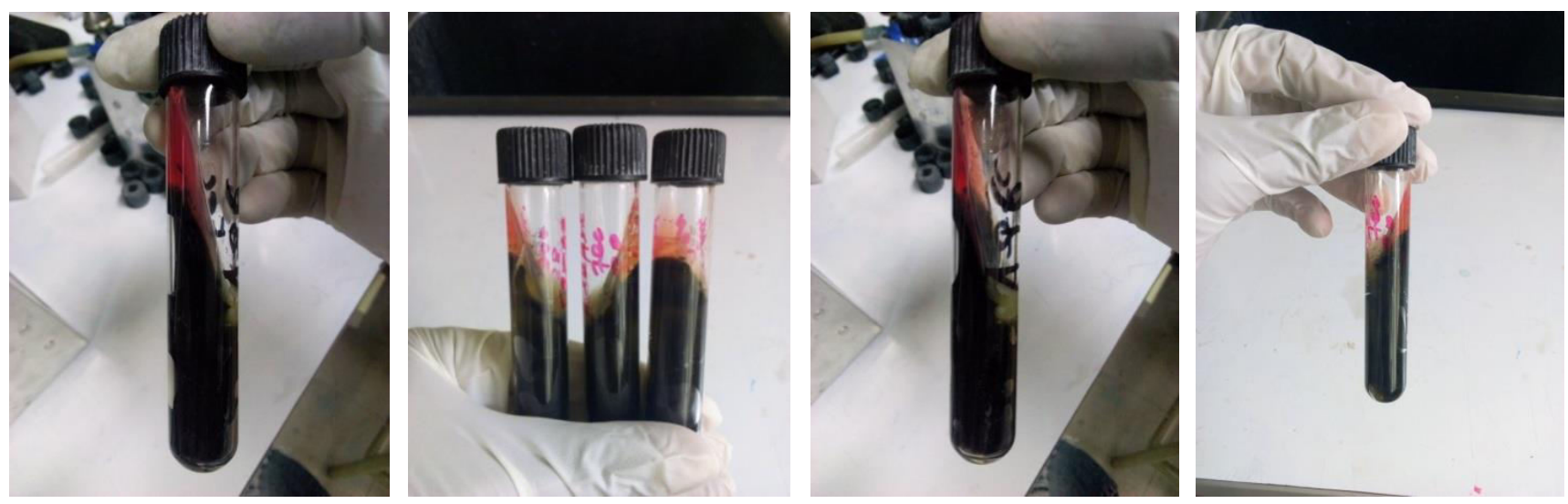

Fig 3: Growth of Salmonella on Triple Sugar Iron Agar (TSI). 
Table 1: Frequency of Salmonella isolated from different sample types in the study area.

\begin{tabular}{|c|c|c|}
\hline Site & Sample type & $\begin{array}{l}\text { Sample } \\
\text { collected }\end{array}$ \\
\hline \multirow{5}{*}{ Adama } & Bulk tank milk & \\
\hline & Feces & \\
\hline & Floor sample & \\
\hline & Hand swab & \\
\hline & Sub total & \\
\hline \multirow{6}{*}{ Modjo } & Bulk tank milk & \\
\hline & Feces & \\
\hline & Floor sample & \\
\hline & Hand swab & \\
\hline & Sub total & \\
\hline & Grand total & \\
\hline
\end{tabular}

There is no statistically significant difference between isolates derived from different sample types of the studied dairy farms $(\chi 2=0.966, \mathrm{p}=0.809)$. From a total of $10(8.5 \%)$ isolates, nine $(90 \%)$ were from Adama and $1(10 \%)$ was from Modjo. There is statistically significant difference between isolates derived from Adama and Modjo of studied sites $(\chi 2=6.012, p=0.014)$ (Table 1).

Antibiotic Susceptibility Testing - All the 10 isolates were tested against ten commonly used antimicrobials (Table 2). All isolates were resistant at least to one or more antimicrobials. Nine of the 10 isolates were resistant to two or more antimicrobials. The antibiotic susceptibility profiles of the isolates showed that the isolates were $60 \%$ resistant to all of the antibiotics which are streptomycin, methicillin and nalidixic acid. Gentamycin was the most effective antibiotic. Ninety percent (9/10) of the isolates were found to be susceptible to gentamycin (Fig 4).

Multi-Drug Resistance Frequency Distribution Among 10 resistant isolates, 8 (80\%) were resistant to two or more antimicrobials (multidrug resistance (MDR)). The large proportion of multidrug resistant isolates $6(60 \%)$ were resistant to four to seven different antimicrobials while the other two resistant isolates were resistant to a single antimicrobial. 2 (6.67\%), 5 (16.67\%), 4 (13.33\%), and $7(23.33 \%)$ were tetra-resistant, quadra-resistant,
No. of positives Percentage of positives $(\%)$

\begin{tabular}{rrr}
6 & 1 & $(16.7)$ \\
46 & 7 & $(15.2)$ \\
5 & 1 & $(20)$ \\
5 & - & - \\
62 & 8 & 12.9 \\
4 & - & - \\
43 & 1 & $(2.3)$ \\
4 & - & - \\
4 & - & - \\
55 & 1 & 1.8 \\
17 & $\mathbf{1 0}$ & $\mathbf{8 . 5}$ \\
\hline
\end{tabular}

hexa-resistant, hepta-resistant, respectively with 11 different resistance patterns. Among 8 MDR isolates, $6(75 \%)$ from feces, 1 (12.5\%) bulk tank milk, and 1 $(12.5 \%)$ floor sample isolates (Table 3).

Sensitivity to antimicrobial agents - Sensitivity test to the ten Salmonella isolates against 10 antibacterial agents was carried out. $60 \%$ of Salmonella isolates were found resistant to streptomycin, methicillin and nalidixic acid, and $90 \%$ of the isolates sensitive to gentamycin (Fig 5).

\section{DISCUSSION}

Salmonellosis is the most common food borne disease in both developing and developed countries, although incidence rates vary according to the country (Stevens et al., 2006). The fecal wastes from infected animals and humans are important sources of bacterial contamination of the environment and the food chain (Ponce et al., 2008).

Salmonella infection in dairy cattle persists to be a major problem worldwide. Considerable economic losses were manifested through mortality and poor growth of infected animals as well as the risk of transmission to humans either through food chain or direct animal contact (Alam et al., 2017). Hence, detection of animals contacting humans and equipment are essential to control Salmonella on farm and its spread to the public (Rotimi et al., 2008). 
Table 2: Antibiotic susceptibility profiles of Salmonella isolates in dairy farms.

\begin{tabular}{lccc}
\hline Types of antimicrobials & \multicolumn{3}{c}{ No. of isolates } \\
\cline { 2 - 4 } Ciprofloxacin $5 \mu \mathrm{g}$ & Resistant $(\%)$ & Intermediate $(\%)$ & Susceptible (\%) \\
Cefoxitin $30 \mu \mathrm{g}$ & 10 & 30 & 60 \\
Gentamycin $10 \mu \mathrm{g}$ & 20 & 0 & 80 \\
Nalidixic acid $30 \mu \mathrm{g}$ & 10 & 10 & 90 \\
Methicillin $5 \mu \mathrm{g}$ & 60 & 0 & 30 \\
Cefuroxime $30 \mu \mathrm{g}$ & 60 & 20 & 40 \\
Erythromycin $15 \mu \mathrm{g}$ & 10 & 30 & 70 \\
Tetracycline $10 \mu \mathrm{g}$ & 50 & 10 & 20 \\
Nitrofurantoin $300 \mu \mathrm{g}$ & 50 & 20 & 40 \\
Streptomycin $10 \mu \mathrm{g}$ & 10 & 00 & 70 \\
\hline
\end{tabular}

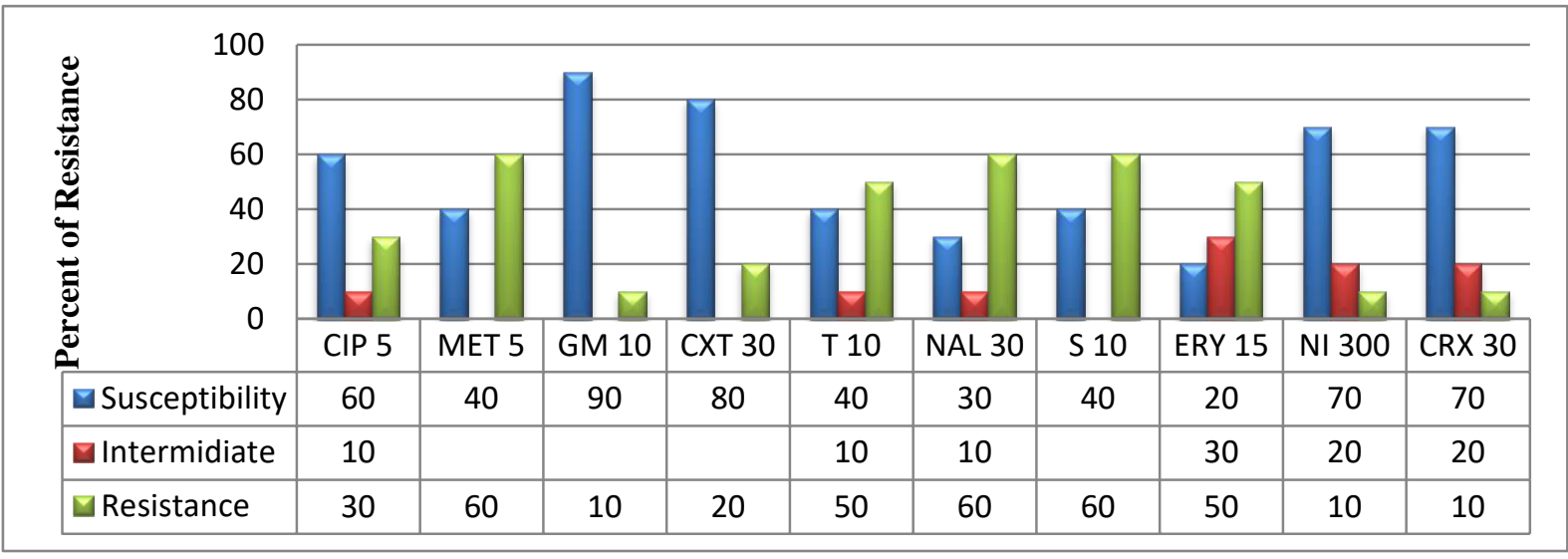

Fig 4: Antimicrobial susceptibility profiles of Salmonella isolates.

Table 3: Multiple antimicrobial resistances of the isolated Salmonella.

\begin{tabular}{ccc}
\hline $\begin{array}{c}\text { Number of antimicrobial } \\
\text { resistances }\end{array}$ & $\begin{array}{c}\text { Antimicrobial resistance patterns } \\
\text { (number of isolates) }\end{array}$ & Number of isolates (\%) \\
\hline Three & 2 & $2(20)$ \\
Four & 3 & $3(30)$ \\
Six & 2 & $2(20)$ \\
Seven & 1 & $1(10)$ \\
\hline
\end{tabular}
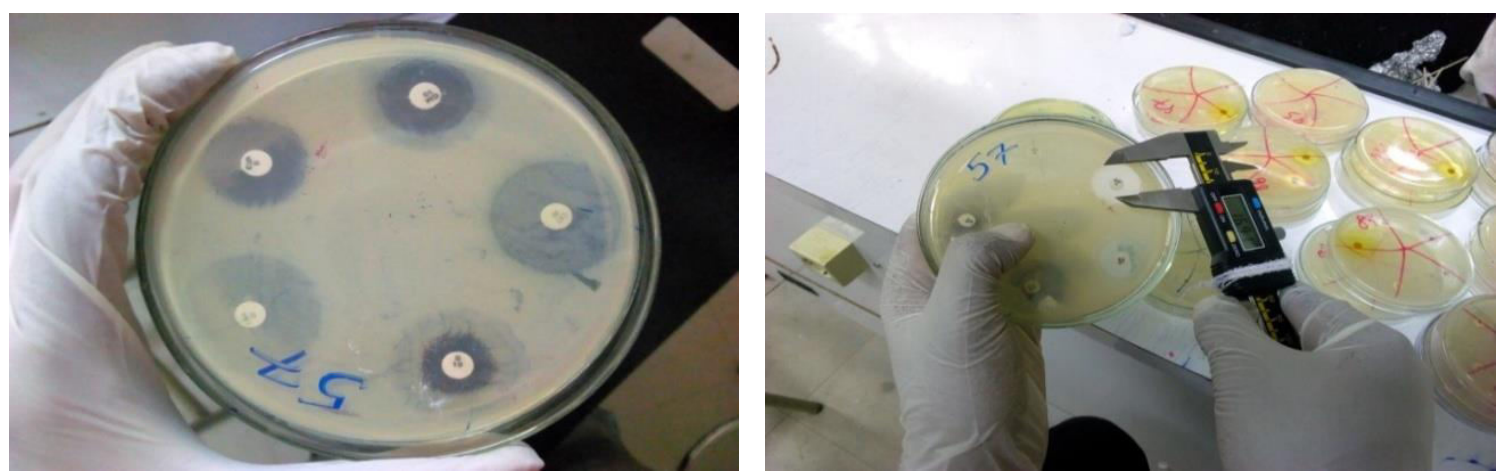

Fig 5: Antimicrobial Susceptibility of Salmonella to Different Antibiotics. 
The present study was conducted to investigate Salmonella from cow's feces, equipment, personnel's hand swab and the contamination of cattle's environment in dairy farms from Adama and Modjo. In this study, the prevalence of Salmonella was (8.5\%) is lower than (20\%) in raw milk from Kersa district; Ethiopia (Tadesse and Anbessa, 2012), (12.5\%) This was relatively comparable with studies conducted in other parts of Ethiopia such as Harar (11.5\%) (Ayalu et al., 2011), Adama (8.6\%), Modjo (10.5\%) (Fufa et al., 2017), and Butajira (10.5\%) (Demissie et al., 2017), but it was higher than another study conducted in Adama (5.7\%), (Beyene et al., 2016) (6.5\%).The variation among the above-mentioned findings might be largely due to substandard environmental and personal hygiene, ignorance of health promotion, and methodological difference (sample size, study design, study period, and diagnostic techniques).

Fecal prevalence of Salmonella among lactating dairy cattle in the current study was $8.98 \%(8 / 89)$ which is higher than the fecal Salmonella isolation rate of $7.7 \%$ in lactating cows and in contact humans in dairy farms of Addis Ababa (Zelalem et al., 2011) and (Fufa et al., 2017). However, it is lower than the fecal Salmonella isolation rate of $9.7 \%$ in United States (Callaway et al., 2005). The current study also revealed $10 \%(1 / 10)$ of Salmonella isolates from bulk tank milk which is lower than that reported by 19\% (4/21) (Fufa et al., 2017) in and around Modjo, but higher than the work of (Teklu and Negussie, 2011) (8.9\%) in slaughtered small ruminants and environment in Modjo export abattoir. The difference in amount and relative occurrence of Salmonella isolate between the present and previous studies at different areas of the Ethiopia could be attributed to difference in risk factors that contribute to the occurrence of Salmonella. These are host related risk factors that include age, breed, the physiological state of the animals, feeding strategies, vaccination status (Liza, 2003). Environment related risk factors such as hygienic and management practice, stocking density, type and amounts of feed, accessible water supplies, usage of contaminated utensils, housing type, ventilation, and movement of animals, calving environment, and production facilities in different areas also play role for Salmonella occurrence (Karin et al., 2011).
Resistance for two or more of antimicrobials (90\%) which was observed in this study was higher than other studies conducted in Ethiopia (Molla et al., 2006; Zelalem et al., 2011), but lower than (96.4\%) (Fufa Abunna et al., 2017).This difference may be due to the increasing rate of inappropriate utilization of antibiotics in the dairy farms which favors selection pressure that increased the advantage of maintaining resistance genes in bacteria (Mathew et al., 2007).

Zewdu and Cornelius (2009) reported that the isolates of Salmonella from food items and personnel from Addis Ababa were resistant to the commonly used antibiotics including streptomycin, ampicillin, and tetracycline. The result of the current research also indicated resistance of Salmonella isolates to commonly used antimicrobials including streptomycin, methicillin and nalidixic acid with resistance rate of $60 \%$ to all of the antibiotics mentioned above (Rahman et al., 2019). Among all isolated Salmonella, in the current study, $60 \%$ of them were resistant to streptomycin.

This finding is lower than other reports (Beshatu Ferede, 2014) (81.8\%), (Zelalem, 2011) (66.7\%), but higher than other reports $(10.7 \%)$, (Beyene et al., 2016) (19.4\%). This finding is higher than the previous report from Addis Ababa (Zelalem et al., 2011) which reported $26.7 \%$ resistance to tetracycline. In the current study gentamycin showed a good antimicrobial activity against $90 \%$ of the tested isolates and one intermediate isolate against this drug was detected. This result is higher than the reports by (Zelalem et al., 2011) from Addis Ababa who reported a resistance rate of $73.3 \%$, but lower than the report by (Fufa et al., 2017).

Among 10 resistant isolates, 8 (80\%) were resistant to two or more antimicrobials (resistant to two or more antimicrobials). This finding is in line with previous report by (Zelalem et al., 2011) from Addis Ababa on lactating dairy cows and in contact humans in dairy farms in which $83.3 \%$ of the isolates were resistant to greater than one antimicrobial agent (s) and all isolated from dairy farm related samples were resistant to at least one antimicrobial agent (Happy et al., 2018). 


\section{CONCLUSION AND RECOMMENDATIONS}

This cross-sectional study showed that Salmonella was isolated $(8.5 \%)$ from dairy farms in Adama (12.9\%) and Modjo (1.8\%) with variable isolation rate. This result is significantly high to be a potential source of food borne Salmonellosis in humans. High proportion (80\%) of Salmonella isolates were resistant to two or more of the antimicrobials that are commonly used in the veterinary and public health set up. This may pose difficulties in the treatment of human clinical cases and other bacterial diseases. Based on the above conclusion the following recommendations are forwarded: Hygiene status of the dairy farms should be improved to minimize cross contamination of Salmonella from milking containers and cattle's environment, Since Salmonella is resistant to most common drugs, attention should be taken in selecting antimicrobials in treating Salmonella infection both in animals and human being based on antimicrobial susceptibility test, Further study ought to be conducted to identify the source of contamination, and Molecular characterization of the isolates with emphasis on resistant strains is also necessary to identify mechanisms of antibiotic resistance.

\section{ACKNOWLEDGEMENT}

The author is thankful to his co-authors who encouraged and supported to the successful research.

\section{CONFLICT OF INTEREST}

The author declares that there is no conflict of interest about the publication of the article.

\section{REFERENCES}

1) Alexander, K., Warnick, L. and Wiedmannm, M. (2009). Antimicrobial resistant Salmonella in dairy cattle in the United States. Vet. Res. Commun. 33: 191-209.

2) Alam Md. Gahangir, Md. Ekhlas Uddin, Sezanur Rahman, Tasnim Ahmad, Mohammad Shakil Mahmood, Pulak Maitra, Md. Sharifull Islam. (2017). Protease activity of the extracellular enzyme produced by $B$. subtilis isolated from soil. Int. J. of Environment, Agri. and Biotechnol. 2(1), 382388. https://doi.org/10.22161/ijeab/ 2.1.48
3) Ayalu AR, Seyoum B, Yimam J. (2011). Antibiotic susceptibility patterns of Salmonella and Shigella isolates in Harar, Eastern, Ethiopia. J. Infect. Dis. Immun. 3: 134-139.

4) Beshatu F. (2014). Isolation, Identification, Antimicrobial Susceptibility Test and Public awareness of Salmonella on Raw Goat Meat at Dire Dawa Municipal Abattior, Eastern Ethiopia.

5) Beyene, T and Tesega, B. (2014). Rational veterinary drug use: Its significance in public health. J. Vet. Med. Hlth. 6: 302-308.

6) Beyene, T., Yibeltie, H., Chebo, B., Abunna, F., Beyi, A., Mammo, B., Ayana, D. and Duguma, R. (2016). Identification and antimicrobial susceptibility profile of Salmonella isolated from selected dairy farms, abattoir and humans at Asella town, Ethiopia. J. Vet. Sci. Techno., 7: 320.

7) Callaway, T., Keen, J., Edrington, T., Baumgard, L., Vanamburgh, K., Poole, T., Harvey, R. and Nisbet, D., (2005). Fecal prevalence and diversity of Salmonella species in lactating dairy cattle in four states. J. Dairy Sci., 88: 3603-3608.

8) Central Statistical Agency (CSA), (2005). Agricultural Sample Survey, (2004/05): Central Statistical Authority No.2. Report on Livestock and livestock characteristics. Statistical Bulletin, Addis Ababa, Ethiopia, Pp. 331.

9) Demissie AT, Wubie TM, Yehuala FM. (2014). Prevalence and antimicrobial susceptibility patterns of Shigella and Salmonella species among patients with diarrhea attending Gondar town health institutions, Northwest, Ethiopia. Sci J. Publ. Heal; 2: 469-475.

10) Fluit, A., (2005): Towards more virulent and antibiotic-resistant Salmonella. FEMS, Immunol. Med. Microbiol., 43, 1-11.

11) Fufa Abunna, Debebe Ashenafi, Takele Beyene, Dinka Ayana, Bedaso Mamo and Reta Duguma., (2017). Isolation, identification and antimicrobial susceptibility profiles of Salmonella isolates from dairy 
farms in and around Modjo town, Ethiopia.Vet. J., 21(2): 92-108.

12) Guibourdenche M., Roggentin, P., Mikoleit, M., Fields, I., Bockemuhl, J., Grimont, P., Weill, F., (2010). Supplement 2003-2007 (No. 47) to the White-Kauffmann-Le Minor scheme. Res. Microbiol., 161, 26-29.

13) Happy A. H., M. G. Alam, S. Mahmud, M. M. Islam, M. R. Ahmed, M. E. Uddin. (2018). Isolation, Identification \& Characterization of Gram-Negative Bacteria from Popular Street Food (Chotpoti) at Savar Area, Dhaka, Bangladesh. Open Access Library J. 5, e4986. https://doi.org/10.4236/oalib.1104986

14) Hendriksen, R. (2003). A global Salmonella surveillance and laboratory support project of the World Health Organization: Laboratory Protocols (Isolation of Salmonella). $\quad\left(4^{\text {th }}\right.$ Edition), Pp. 253-278.

15) Hoffmann S., M.B.Batz, and J.G.Morris Jr. (2012). "Annual cost of illness and qualityadjusted life year losses in the united states due to 14 foodborne pathogens,"Journal of Food Protection, 75(7): 1292-1302.

16) Karin H., Andrea I., and Martin W. (2011). Animal contact as a source of human nontyphoidal Salmonellosis. J. Vet. Res., 42, 128.

17) Kemal J. (2014). "A review on the public health importance of bovine Salmonellosis," J. of Veterinary Science and Technology, 5(2): e1000175.

18) Kirk M.D., Pires S.M., and Black R.E. (2015). "World Health Organization estimates of the global and regional disease burden of 22 foodborne bacterial, protozoal, and viral diseases 2010: a data synthesis," PloS Medic. 12(12): e1001921.

19) Kusumaningrum, H., Riboldi, G.,Hazeleger, W. and Beumer, R., (2003). Survival of food borne pathogens on stainless steel surfaces and cross-contamination to foods. Int J. Food Microbiol. 85: 227-236.

20) Liza, R., (2003). Salmonella Dublin in dairy cattle, use of diagnostic tests for investigation of risk factors and infection dynamics. PhD Thesis, Dept. of Animal Science and Animal
Health, the Royal Veterinary and Agricultural University, Copenhagen. Pp. 13-121.

21) Mathew AG, Cissell R, Liamthong S. (2007). Antibiotic Resistance in Bacteria Associated with Food Animals: A United States Perspective of Livestock Production. Foodborne. Path Dis, 4:115-133.

22) McCuddin, Z.P., Carlson, S.A., Rasmussen, M.A., and Franklin, S.K. (2006). Klebsiella to Salmonella gene transfer within rumen protozoa: implications for antibiotic resistance and rumen defaunation. Vet. Microbiol. 114: 275-284.

23) Md. Ekhlas Uddin, Pulak Maitra, H. M. Faruquee, Md. Firoz Alam. (2014). Isolation and Characterization of Proteases Enzyme from Locally Isolated Bacillus sp. American J. of Life Sciences. 2(6): 338-344. https://doi.org/10.11648/j.ajls.20140206.12

24) Molla W, Molla B, Alemayehu D, Muckle A, Cole L, Wilkie E. (2006). Occurrence and antimicrobial resistance of Salmonella serovars in apparently healthy slaughtered sheep and goats of central Ethiopia. Trop Anim Health Prod, 38: 455-62.

25) Ponce E, Khan AA, Cheng CM, Summage WC, Cerniglia CE. (2008). Prevalence and characterization of Salmonella enterica serovar Weltevreden from imported seafood. Food Microbiology, 25: 29-35.

26) Pui C.F., Wong W.C., Chai L.C. (2011). "Salmonella: a foodborne pathogen. International Food Research J., 18(2): 465-473.

27) Rahman MA, Haque A, Ahmad T, Mahmud S, Hossain MR, Barman NC, Uddin ME, and Ahmed R. (2019). Isolation, Identification and Antibiotic Sensitivity Pattern of Salmonella spp. from Locally Isolated Egg Samples. Amer. J. of Pure and Appl. Biosci., 1(1), 1-11. https://doi.org/10.34104/ajpab.019.019111

28) Rotimi VO, Jamal W, Pal T, Sonnevend A, Dimitrov TS, Albert MJ (2008). Emergence of multidrug-resistant Salmonella spp. and isolates with reduced susceptibility to ciprofloxacin in Kuwait and the United Arab Emirates. Diagn. Microbiol. Infect. Dis., 60: 71-7. 
29) Shahen MZ, Mahmud S, Imran MAS, Islam MM, Islam MR, Uddin ME and Alam MS. (2019). Effect of Antibiotic Susceptibility and Inhibitory Activity for the Control of Growth and Survival of Microorganisms of Extracts of Calendula officinalis. Europ. J. of Med. and Health Sci., 1(1), 1-9. https://doi.org/10.34104/ejmhs.019

30) Sharif IH, Mosaib MG, Haque MA, Jamal MAHM, and Uddin ME. (2019). Assessment and Biomonitoring of the Effect of Rapeseeds Oil on Wister Rat Organs. Amer. J. of Pure and Appl. Biosci., 1(4), 20-29. https://doi.org/10.34104/ajpab.019.0192029

31) Stevens A, Kabore Y, Perrier-Gros-Claude JD, Millemann Y, Brisabois A, Catteau M, Cavin J, Dufour B. (2006). Prevalence and antibiotic-resistance of Salmonella isolated from beef sampled from the slaughterhouse and from retailers in Dakar (Senegal). Int J. Food Microbiol, 110: 178-86.

32) Tadesse, T. and Anbessa, D., (2012). Prevalence and antimicrobial resistance of Salmonella isolated from raw milk samples collected from Kersa District, Jimma Zone, South-West Ethiopia. J. Med. Sci., 12, 224228.

33) Teklu, A. and Negussie, H., (2011). Assessment of risk factors and prevalence of Salmonella in slaughtered small ruminants and environment in an export abattoir, Modjo, Ethiopia. American-Eurasian J. Agric. Environ. Sci., 10, 992-999.
34) Threlfall E. J., (2002). “Antimicrobial drug resistance in Salmonella: problems and perspectives in food- and water-borne infections," FEMS Microbiology Reviews, 26(2): 141-148.

35) Uddin M. E., Ahmad T., Ajam M. M., Moniruzzaman M., Ray S. K., Sufian A., and Ahammed T. (2017). Thermotolerant Extracellular Proteases Produced by Bacillus subtilis Isolated from Local Soil that Representing Industrial Applications. J. of Pure and Applied Microbiology. 11 (2), 733741, https://doi.org/10.22207/JPAM.11.2.12

36) Van Boeckel T. P., Brower C., Gilbert M. (2015). "Global trends in antimicrobial use in food animals," Proceedings of the National Academy of Sciences of the United States of America, 112(18): 5649-5654.

37) Zelalem Addis, Nigatu Kebede, Zufan Worku, Haile Gezahegn, Alehegne Yirsawand Tesfu Kassa (2011). Prevalence and antimicrobial resistance of Salmonella isolated from lactating cows and in contact humans in dairy farms of Addis Ababa: a cross sectional study. BMC Infectious Diseases, 11: 222.

38) Zewdu E, Cornelius P. (2009). Antimicrobial resistance pattern of Salmonella serotypes isolated from food items and personnel in Addis Ababa, Ethiopia. Trop. Anim. Health. Pro., 41: 241-9.

Citation: Abrar A, Beyene T, and Furgasa W. (2020). Isolation, identification and antimicrobial resistance profiles of Salmonella from dairy farms in Adama and Modjo towns, central Ethiopia. Eur. J. Med. Health Sci, 2(1), 1-11. https://doi.org/10.34104/ejmhs.02001011 (c) (9) 